\title{
PRESERVAR E RESISTIR: A LUTA DOS PESCADORES ARTESANAIS EM DEFESA DO TERRITÓRIO PESQUEIRO DO LAGO DO MAICÁ, EM SANTARÉM-
} PA

\author{
PRESERVE AND RESIST: THE FIGHT \\ OF CRAFTFISHERMEN IN DEFENSE \\ OF THE FISHERY TERRITORY OF \\ MAICA LAKE, IN SANTARÉM-PA
}

\author{
Wandicleia Lopes de Sousa \\ wandicleia@hotmail.com. \\ Economista, Mestra em Sociedade, Ambiente e Qualidade de Vida pelo PPGSAQ/UFOPA. Consultora da \\ Sociedade para a Pesquisa e Proteção do Meio Ambiente (Sapopema/Santarém). \\ Rubens Elias da Silva \\ hellazer09@gmail.com \\ Docente do Programa de Pós-Graduação em Sociedade, Ambiente e Qualidade de Vida edo Programa de \\ Ciências da Sociedade da Universidade Federal do Oeste do Pará. Atualmente é professor associado da \\ Universidade de Québec, Canadá. \\ Thiago Almeida Vieira \\ thiago.vieira@ufopa.edu.br \\ Docente do Programa de Pós-Graduação em Sociedade, Ambiente e Qualidade de Vida- PPGSAQ e do \\ Programa de Pós-Graduação em Sociedade, Natureza e Desenvolvimento (PPGSND), ambos da Universidade \\ Federal do Oeste do Pará.
}

\section{RESUMO}

Este artigo trata da resistência de pescadores de Santarém,no Pará,para a preservação do lago do Maicá que representa os modos de criar, fazer e viver desse grupo. Busca-se entender como ocorre o processo organizativo de resistência dos pescadores que vivem às margens do referido lago em defesa de seu espaço de cultura e subsistência. As relações engendradas por pescadores serão analisadas e discutidas a partir das lentes das categorias analíticas do território, gerenciamento pesqueiro e mobilizações políticas. Santarém tem sido palco de intensos conflitos socioambientais, especialmente na questão pesqueira onde pescadores artesanais têm lutado para regulamentar o acesso aos recursos pesqueiros nas regiões lacustres do município, em especial, no lago do Maicá. Como resultado, aponta-se que a atividade da pesca artesanal desenvolve função essencial na dinâmica econômica, social e ambiental na região do oeste do estado do Pará, é responsável direta pela garantia da segurança alimentar e nutricional da população local, além de garantir a manutenção e preservação do lago do Maicá.

Palavras-Chave: Pescadores Artesanais. Resistência. Preservação.

\section{ABSTRACT}

This article deals with the resistance of fishermen from Santarém, Pará, for the preser- 
vation of Maicá Lake, which represents the ways of creating, doing and living in this group. It seeks to understand how the organizational process of resistance of the fishermen of Maicá Lake in defense of their space of culture and subsistence occurs. The relationships engendered by fishermen will be analyzed and discussed from the lens of the territory's analytical categories, fisheries management and political mobilizations. Santarém has been the scene of intense socio-environmental conflicts, especially in the fishing area where artisanal fishermen have struggled to regulate the access to fishing resources in the lake regions of the municipality, especially in Maicá Lake. As a result, it is pointed out that the activity of artisanal fishing develops an essential function in the economic, social and environmental dynamics in the western region of Pará State, is directly responsible for guaranteeing the food and nutritional security of the local population, besides ensuring the maintenance and preservation of Maicá Lake.

Keywords: Artisanal Fishermen. Resistance. Preservation.

\section{INTRODUÇÃO}

Por meio deste artigo busca-se desenvolver uma caracterização do processo de luta e resistência dos pescadores artesanais de Santarém em defesa do Lago do Maicá, na região oeste do estado do Pará. Dessa forma, entender como ocorre o processo organizativo dos pescadores e sua metodologia de resistência em defesa de seu espaço pesqueiro são essenciais para ajudar no debate e (re)formulação de políticas públicas, bem como no fortalecimento da categoria frente às externalidades que respondem diretamente a interesses empresariais estritamente ligados ao capital globalizado, em contextos de injustiça ambiental. $\mathrm{O}$ estudo foi norteado pela seguinte pergunta: como os pescadores artesanais se articulam e criam formas de resistência em defesa do Lago do Maicá?

Neste artigo serão discutidas as categorias analíticas território, gerenciamento pesqueiro e mobilização política enquanto variáveis interdependentes para compreender o processo de transformação social ocorrente nas comunidades pesqueiras situadas às margens do lago, face ao projeto de desenvolvimento regional de empresas graneleiras e o escoamento de commodity, por meio do porto a ser instalado na região do Maicá.

O território é uma categoria analítica pensada a partir do espaço, sendo que aquele é apropriado, dividido e embotado de significados culturais e históricos pela agência humana. Sendo assim, o território seria uma construção social investida de poder, este criado e recriado continuamente pelos atores ao longo do tempo (RAFFESTIN, 1993). Como frisado por Saquet (2006), também não se pode esquecer a multidimensionalidade da abordagem de Raffestin em relação ao que este autor denominou sistema territorial, como fruto do resultado de relações de poder do Estado, de empresas, organizações e de indivíduos, isto é, de relações diárias, ligadas à dinâmica política, econômica e cultural, que constituem malhas (conjunto de pontos e ligações/conexões entre diferentes agentes sociais), nós (pontos de encontro de relações sociais) e redes (ligações entre dois ou mais agentes sociais).

Sistema territorial é o dispositivo multidimensional onde se articulam relações de poder do Estado, de empresas, organizações e de indivíduos, entremeadas cotidianamente e legitimadas pela ação política, econômica e cultural. Sendo assim, o território é o espaço apropriado, onde os atores sociais não apenas exercem relações visando as satisfações de necessidades sociais; além disso, o território é o dispositivo mental onde a cultura se processa, se ajusta, se reorganiza ao longo do tempo. Os pescadores artesanais do Maicá construíram o sistema territorial no lago e suas margens, onde a vida comunitária se processa e se distribui: é do lago que se extrai o pescado, a água para alimentar a família e os animais domésticos; é nele em que a 
cultura lacustre se faz e se tem sentido: as histórias, as oralidades, os seres sobrenaturais, os seres antropomórficos, as religiosidades.

Dentre os territórios de produção pesqueira que existem dentro do município de Santarém, o Lago do Maicá possui aproximadamente $161 \mathrm{~km}^{2}$ de extensão, passando por diversos bairros e comunidades. Essa área possui características que se assemelham a região de várzea, pois, é composto por um sistema de lagos oriundos do "Rio Amazonas com forte influência do Rio Tapajós através da restinga que divide a região em Ituqui e Maicá e áreas de terra firme próximas a cidade de Santarém" (VAZ, 2016, p.14-15) e grande parte do seu território está inserido na área urbana.

Diante do processo de produção e reprodução do capital global, verificamos que a vida dos pescadores vem passando por constantes transformações sociais, geralmente agenciadas por atores coletivos externos à região e alheios à realidade socioeconômica local. Dessa forma, pretende-se com este estudo discutir o processo de resistência dos pescadores artesanais em defesa do Lago do Maicá, em Santarém, bem como, sobre a importância do lago como espaço de produção e reprodução sociais e imprescindível na vida desses atores sociais.

Em outro estudo realizado sobre os impactos socioambientais no Lago do Juá, em Santarém, os pesquisadores discutem as tensas relações entre os moradores locais do Lago do Juá e os pescadores artesanais oriundos de diferentes áreas do município de Santarém, Estado do Pará, ocasionando determinados impactos socioambientais. (CARDOSO et al., 2018). Esses impactos são percebidos como superpostos em escalas na degradação do lago e na escassez de estoques pesqueiros. Sendo assim, a pressão e degradação dos lagos no município não são recentes. No entanto, diferentemente do Juá, o Maicá sofre pressões externas vinculadas às grandes empresas que usam o poder econômico para se impor mediante o Estado e os governos em diversas escalas, num claro cenário de injustiça social. A injustiça ambiental se efetua em contextos de desigualdade de acesso a direitos sociais garantidos pela constituição federal, impondo-se o poder econômico e de acesso à justiça, relegando principalmente os grupos sociais historicamente discriminados à maior parcela dos danos ambientais. (PINTO et al., 2014).

A atividade da pesca artesanal tem uma ligação muito forte com o ambiente, redimensionando as intensas e complexas relações entre sociedade e a natureza. Isto confirma as palavras de Diegues (2001) "[...] outras representações mentais são construídas para tornar compreensíveis as experiências e seres da natureza, por exemplo, peixes, sua natureza e suas relações com os humanos [...]" (DIEGUES, 2001, p. 42). Sendo assim, o cotidiano das comunidades da região é construído e reelaborado a partir das relações ecológicas que essas comunidades estabelecem com o lago, em suas sucessivas estações ao longo do ano (verão amazônico, vazante e período de cheia) e a necessidade de conservar o lago e seus estoques pesqueiros.

No cenário onde a globalização e a relação do poder econômico são hegemônicos, as comunidades ribeirinhas lutam para resistir às transformações que esses modelos podem/causam em seus modos de vida e principalmente ao meio ambiente. (CHEREM; AZEVEDO, 2016). Os pescadores artesanais, por meio de sua Colônia de Pescadores Z-20, mobilizaram-se em parceria com outras entidades da sociedade civil organizada, Conselho de Pastoral dos Pescadores (CPP), Organizações Não Governamentais (ONGs), e instituições públicas jurídicas, como forma de resistir às mudanças que os detentores do poder impõem, sobretudo para garantir o respeito aos seus direitos frente ao Estado. 
Quando falamos anteriormente em malhas, nós e redes ligadas ao conceito de território em Raffestin (1993), podemos contextualizar essas nomenclaturas ao nosso estudo de caso. As malhas processam-se aqui enquanto os feixes de relações entre pescadores artesanais mediante o risco de perda do território onde a vida social se faz e se processa. Os contatos, o disse-me-disse, as reuniões nos barracões da comunidade. Os nós já sugerem uma gama de relações mais complexas, tensas e que obriga as comunidades a se relacionarem com instituições legitimadas pela ordem do Estado, como o serviço jurídico-institucional, os órgãos ligados ao meio ambiente, as próprias empresas interessadas na criação do porto no lago, criando redes de mais diferentes intencionalidades.

\section{ORGANIZAÇÃO HISTÓRICA DOS PESCADORES ARTESANAIS EM SANTARÉM}

Em meados de 1920, os pescadores artesanais começaram a se organizar por meio de suas colônias de pescadores, em nível local; de suas federações, em nível estadual; e a confederação, em nível nacional, por intervenção da Marinha Brasileira. Essa organização se deu pela orientação do Estado que tinha a finalidade de manter os pescadores sobe a sua coordenação, por isso, inicialmente seu costume era de entidade assistencialista, administrativa e militar. (KALIKOSKI et al., 2009; SILVA, 1991).

Então, a Marinha do Brasil começa a intervir editando normas aos pescadores artesanais para que estes comecem a realizar o registro de suas embarcações nas unidades da Capitania dos Portos, e o monitoramento de suas atividades ficou sob a responsabilidade do Ministério da Agricultura. A maioria das entidades de pescadores artesanais era coordenada por comerciantes, vereadores, deputados, militares, empresários e outras categorias que tinham interesse apenas de ter o controle sobre a classe pescadora, o que as tornou organização simplesmente assistencialista. (AMORIM, 2014).

Na década de 1960, os pescadores começaram um processo organizativo por meio do Conselho de Pastoral dos Pescadores (CPP), fundado em Pernambuco, com a finalidade capacitar e ajudar na organização dos pescadores artesanais. Esse fato proporcionou uma mudança na organização política da classe, que até então estavam sob o domínio dos militares e empresários. Essas mudanças começaram pelas regiões do Norte e Nordeste e foram se fortalecendo na luta não apenas na construção da identidade política da categoria, mas disseminou-se como movimento contra a ditadura militar. A presença do CPP, do Movimento de Educação de Base - MEB e da Federação dos Órgãos de Assistência Social e Educacional - FASE foram essenciais para o êxito no processo de conquista das colônias pelos pescadores. (LEROY, 1988).

Em 2005, o Brasil possuía aproximadamente 1.000 Colônias de Pescadores e no estado do Pará são 65 colônias de pescadores ligadas à Federação dos Pescadores do Estado do Pará (FEPA) e ao Movimento dos Pescadores do Estado do Pará (MOPEPA), e em nível nacional a relação é feita com a Confederação dos Pescadores do Brasil. (SANTOS, 2005). No interior do Estado, a região do Baixo Amazonas possui 13 entidades que agregam mais de 70 mil pescadores artesanais, que têm em sua história marcas de lutas, resistência, organização e construção de instrumentos de gestão participativa.

Em março de 1920, é fundada em Santarém a Colônia de Pescadores Z-20, pelo cruzador Frederico Vilar. (LEROY, 1988). Na década de 1980, os pescadores motivados pelo processo de conquista do Sindicato dos Trabalhadores e Trabalhadoras Rurais - STTR, pelos agricultores familiares, iniciaram 
um processo sistemático de formação para conquista da colônia, que até então estava sob a coordenação dos empresários e comerciantes locais. Essa ação ocorreu tendo um elemento religioso-institucional e educativo: foi acompanhado por organizações eclesiais ligados a Igreja Católica, como "[...] a organização da base a partir das comunidades que permitiu a criação de uma corrente intercomunitária e a mobilização da categoria em torno de lutas". (GAMA, 2016, p.114-115).

Alicerçados pelos fundamentos da Igreja e das entidades que os apoiavam, os pescadores concorreram a eleição da entidade e foram vitoriosos, pois, despertaram para a compreensão de que a colônia era uma "[...] ferramenta importante para a organização da base da categoria, garantindo, dessa forma, a defesa permanente dos legítimos direitos e interesses[...]". (GAMA, 2016, p.116). Inicialmente a finalidade principal dos pescadores foi a conquista da direção da colônia, no entanto, para Leroy (1988), o pano de fundo desta luta era garantir a recuperação da "identidade coletiva dos pescadores" ajudando na autoafirmação da classe como uma importante atividade econômica e "como cidadãos politicamente questionadores de ordem social imposta localmente pelas classes dominantes". (LEROY, 1988, p. 38).

Essa conquista foi um marco na história da Colônia de Pescadores Z-20 em Santarém.Desde então, a entidade passou a ser comandada por pescadores artesanais tornando-se referência de luta e resistência coletiva em defesa dos direitos da classe em todo o Estado. Hoje a colônia possui aproximadamente 8.023 filiados que estão ativos nos seus 106 núcleos de base organizados em todo o município de Santarém. A organização institucional da Colônia de Pescadores Z-20, é composta por diretores executivos, conselho fiscal e os núcleos de base que dividem a responsabilidade de coordenar a luta em defesa dos pescadores artesanais. Assim,

\footnotetext{
O núcleo de base é um órgão executivo da Z-20/STM, sob a direção da Diretoria Executiva, nas comunidades, que congregam associados de uma única comunidade ou núcleos de associados de várias comunidades, sendo escolhido (a) dois ou mais associados (as), pelos sócios do respectivo Núcleo de Base, para concorrer ao cargo de coordenador. (COLÔNIA DE PESCADORES Z-20, 2012, p. 9).
}

Nessa estrutura a entidade está organizada em suas bases comunitárias, o que os auxilia na identificação das ameaças sofridas e contribui no fortalecimento da classe. Dos filiados à Colônia, quase 5.243 pescadores assinaram o requerimento para receber o benefício do seguro defeso do ano de 2016, contribuindo significativamente com aproximadamente $\mathrm{R} \$ 19.650 .764,00 \mathrm{com}$ a economia do município. Isso demonstra o quanto essa atividade é importante para a dinâmica econômica em Santarém.

Outro fato importante que fortaleceu politicamente os pescadores artesanais do Lago do Maicá foi a fundação da Associação do Movimento dos Pescadores do Baixo Amazonas (MOPEBAM), ocorrida em 1996. Criado com objetivo de fazer a articulação e capacitação para que os pescadores fossem empoderados em suas lutas em defesa do seu território (CARTILHA COLÔNIA DE PESCADORES, 2004). As entidades ligadas aos pescadores em nível local, regional e nacional são responsáveis de fortalecer a luta em defesa da categoria, bem como garantir que sejam assegurados os seus direitos sociais e previdenciários. 


\section{O PROCESSO DE RESISTÊNCIA DA PRESERVAÇÃO DOS RECURSOS PESQUEIROS}

Dentro do arcabouço de leis que regulamentam o uso do recurso pesqueiro, existem normas construídas institucionalmente e as comunitárias; entre essas, merecem destaque os acordos de pesca comunitários, que desde a década de 1970 vêm sendo incorporados pelos pescadores artesanais como importante regra para gestão do território pesqueiro. Os acordos de pesca são modelos de gestão comunitária de lagos cujos estoques pesqueiros são alvo de disputa entre diversos atores sociais, geralmente não pertencentes a comunidades diretamente ligadas ao cotidiano lacustre. Esses acordos começaram a ser implantados devido às fortes pressões ocorridas no estoque pesqueiro nesse período.Além disso, a crescente onda de desmatamento nas "florestas de várzea" e a "expansão da pecuária" geraram uma transformação nos ambientes de reprodução pesqueira.(ALMEIDA, 2006).

Pessanha (2003) investiga o processo de produção econômica de um grupo de pescadores na praia de Itaipu, em Niterói, Estado do Rio de Janeiro, a partir de uma perspectiva antropológica analítica. Essa análise busca compreender os laços invisíveis de produção econômica a partir da história comunitária, os usos sociais dos territórios costeiros, a incerteza da pesca e a variação do mercado, além das condições de trabalho e os direitos emergentes na década de 1970 para esta categoria social. Em certa medida e resguardadas as variantes ecológicas e determinações históricas, os usos dos territórios pesqueiros na região do Lago do Maicá vivenciam situações de semelhança com a comunidade investigada por Pessanha: história ecológica e história comunitária que se entrelaçam, dado que a região de conflito açambarca a região do Ituqui (PA), região fartamente estudada por arqueólogos. (ROOSEVELT et al., 1991; SILVEIRA; SCHAAN, 2005; SILVA; SANTOS, 2018).

Na década de 1990, as comunidades da região amazônica começaram a adotar acordos de pesca como instrumento de ordenamento pesqueiro. Esse é um modelo de gestão comunitária muito eficaz, uma vez que as normas são construídas de forma participativa e coletiva com todos os atores envolvidos (comunitários, entidades representativas de classe e o Estado). A finalidade de modelo de gestão é mitigar a "[...] pressão no estoque pesqueiro por meio de normas, as quais regulamentam o limite (quantidade) de peixes que cada pescador deverá capturar no lago [...]", para garantir a conversão reprodução pesqueira(SOUSA, 2017, p. 30). Após todo o processo interno na comunidade, elaboração e pactuação das normas, é confeccionada uma ata de reunião na qual todos assinam, como forma de comprometer-se a respeitar o acordo de pesca. (CASTRO; MCGRATH, 2001).

Uma das primeiras comunidades na região do Baixo Amazonas a elaborar e formalizar seu acordo de pesca junto ao IBAMA, está inserida no Lago do Sapuacuá, em Oriximiná (PA). Esse foi um processo importante para fortalecer a gestão comunitária. Seguindo essa experiência exitosa, em 1999, a Região do Maicá construiu seu acordo de pesca comunitário, resultado do empenho conjunto das organizações que atuavam no processo de organização comunitária, como o Instituto Amazônico de Manejo Sustentável dos Recursos Ambientais (IARA), Colônia de Pescadores Z-20 e os órgãos governamentais. (CERDEIRA,2002). Essa foi uma experiência que motivou outras comunidades da cidade a elaborarem seus acordos de pesca. (CERDEIRA e CAMARGO, 2008, p. 4489-4492). 


\begin{abstract}
A região do Maicá vem realizando manejo de pesca desde 1972. Ela integra as várias regiões pesqueiras de Santarém (PA), e é constituída por 21 comunidades. [...] Em 1999, os comunitários da região do Maicá elaboraram seu primeiro acordo de pesca. Atualmente, com o fortalecimento do sistema de gestão participativa, os ribeirinhos que antes discutiam e acordavam regras de pesca somente entre si, vêm participando de uma discussão mais ampla onde comunidades vizinhas, instituições governamentais e não governamentais e os pescadores profissionais através das Colônias de Pescadores, discutem e geram propostas de manejo de pesca e fiscalização (4489-4492).
\end{abstract}

Esse novo modelo de gestão comunitária participativa foi normatizado pelo IBAMA, por meio, da Instrução Normativa n ${ }^{\circ} 29$, de 1] de janeiro de 2003, e em seu Art. $1^{\circ}$ que regulamenta os acordos de pesca como sendo um "conjunto de medidas específicas decorrentes de tratados consensuais entre os diversos usuários e o órgão gestor dos recursos pesqueiros em uma área definida geograficamente". (BRASIL, 2003). Assim, essa regulamentação tem efeito apenas em um determinado território, fazendo com que cada comunidade e/ou região crie suas próprias regras de uso do recurso pesqueiro.

No entendimento de Cerdeira e Camargo (2008), os "recursos pesqueiros são bens de domínio público, de uso comum e livre acesso, sendo inviável pensar em privatização dos recursos, ou mesmo, medidas de controle de acesso". (CERDEIRA; CAMARGO, 2008, p.495). Dessa forma, a luta dos pescadores é garantir a conservação para as presentes e futuras gerações, seguindo assim o que está descrito na Portaria IBAMA/PA n 16/1999, acordo de pesca, que regulamenta o período adequado para pesca e para reprodução das espécies existentes no lago.

Com base no entendimento das normas institucionais e comunitárias que os pescadores da Região do Maicá cuidam de seu recurso de forma coletiva, na tentativa de garantir o equilíbrio do ecossistema, a reprodução do estoque pesqueiro essencial para a sobrevivência das famílias. Por exemplo, os pescadores artesanais reúnem-se mensalmente em seus nove núcleos de base com a finalidade de discutir as demandas e socializar as deliberações do conselho de pesca, planejarem as ações a serem realizadas no lago do Maicá. Além de deliberarem sobre as questões particulares da classe.

\title{
EMPODERAMENTO E CONSTRUÇÃO DO PROTOCOLO DE CONSULTA PELOS PESCADORES ARTESANAIS
}

No bojo desse processo de preservação dos estoques pesqueiros do Lago do Maicá, as dimensões intersubjetivas e intrassubjetivas dos atores sociais foram articulando elementos políticos, culturais e de mobilizações de interesses convergentes: preservar o lago para preservar a permanência das comunidades no entorno do lago. Sendo assim, o empoderamento desses atores foi um processo convergente entre mobilização política e demandas sociais e culturais. Para Gohn (2005), trata-se de processos que tenham a capacidade de gerar processos de desenvolvimento autossustentável, com a mediação de agentes externos, sem articulações políticas mais amplas, principalmente com partidos políticos ou sindicatos.

Com base nos pressupotos de Gohn (2004, p. 336)o conceito de empoderamento "empowerment" compreende o processo por meio do qual, pessoas, organizações e comunidades adquirem controle sobre questões de seu interesse, 
e o aumento da capacidade dos indivíduos se sentirem influentes nos processos que determinam suas vidas. No nosso estudo de caso, o empoderamento dos pescadores artesanais deu-se dentro de moldes dos sistemas representativos tradicionais da categoria, talvez oportunizado pela forte presença da colônia como eixo articulador de negociação de interesses da categoria social com as entidades público-privada.

O empoderamento dessas comunidades está relacionado com a história e memória ligadas ao lago, como vetor de sociabilidades e cultura simbólica. Observa-se que essas sociabilidades se interdependem através de ideias como respeito, solidariedade e camaradagem nas relações estabelecidas com atores de dentro e de fora da comunidade. É uma estratégia eficaz para lidar com tensões e conflitos que margeiam toda a rede de negociação presente nesse tipo de processo de embate político.

Os conflitos relacionados ao acesso, uso e usufruto dos recursos naturais ocorrem em espaços habitados há várias gerações por grupos comunitários, que reivindicam a permanência em seu território. Sem dúvida, esses conflitos têm dimensões políticas, sociais e jurídicas (LITLLE, 2001), uma vez que essas comunidades são instadas a se mobilizarem de modo a discutir soluções para problemas coletivos, garantir a continuidade da sua cultura pesqueira e assegurar o acesso a direitos. É nessa conjuntura estrutural que enfatizamos a natureza socioambiental desses conflitos, pois decorrem quando estão envolvidos grupos sociais com modos diferenciados de apropriação, uso e significado do território, ou seja, quando, pelo menos, um dos grupos sofre ameaças quanto à continuidade das formas sociais de apropriação do seu meio, já que território compreende o espaço apropriado e ressignificado pelas relações de poder das variadas dimensões sociais. (PINTO et al., 2014).

O modo de vida dos pescadores artesanais tem grande relação com o ambiente natural do qual depende sua sobrevivência, pois, tem domínio dos ciclos das espécies da fauna e da flora existe nesse ambiente. (SILVA, 2012). Para literatura esse é considerado um conhecimento tradicional no qual "[...] o homem dialoga com a natureza para dela retirar seu sustento [...]". (SOUSA, 2017, p. 60-61). Dessa forma, os pescadores vivem em constante luta em defesa desse ambiente, para garantir que não haja alteração que provoque problemas sociais, econômicos e ambientais em sua vida. Essas lutas ocorrem dentro "[...] da classe ou com a eminência de graves ameaças a sua existência, ocasionando conflitos nos interesses dos atores envolvidos [...]". (SOUSA, 2017, p. 60-61). Por isso, o conhecimento das regulamentações que ordenam o uso do recurso e demais normas fortalecem suas lutas e conquistas em defesa do equilíbrio do ecossistema e na garantia de sua qualidade de vida.

Desde a virada do milênio, a cidade de Santarém passou a compor a estratégia do agronegócio brasileiro tornando-se umas das cidades-polo de implantação de grandes empreendimentos como portos graneleiros, provocando intensos debates e conflitos, entre as organizações comunitárias de (pescadores, quilombolas, indígenas, entre outros) e as instituições privadas e públicas. Em 2003, acompanhando essa estratégia foi implantado o primeiro Porto Graneleiro, fato que impulsionou a chegada de produtores de grãos estimulando assim a produção de grãos na cidade. Ressalta-se que a implantação de um empreendimento desse porte provocou "[...] impactos positivos e negativos a nível social, econômico e ambiental". (SOUSA, 2017, p. 57).

A partir disso, a cidade tornou-se palco de "forte pressão" dos governos municipal, estadual e federal e da iniciativa privada para a construção de estradas, portos, hidrelétricas e estabelecimento de polos de mineração 
como modelo de desenvolvimento e progresso para a região. Contudo, esse modelo econômico possui, como premissa, a exploração dos recursos naturais, causando, assim, o esgotamento do ecossistema. (SOUSA, 2017, p. 38). Em meados de 2012, uma nova proposta de grande investimento para ser instalado na extensão do Lago do Maicá, agora dessa vez, a construção do segundo Porto Graneleiro para auxiliar no escoamento da produção de soja e milho produzido no centro-oeste do país. Porém, essa definição traz consigo a possibilidade de resultados danosos para a população local e de modo especial aos pescadores que dependem desse ambiente para sua sobrevivência.(SILVA, 2014).

Com a nova proposta de implantação do porto, emergem conflitos entre os pescadores, moradores, instituições governamentais e representantes da empresa, inclusive mudando o convívio social dentro na região. O motivo principal desses conflitos é a percepção antinômica do que o lago representa e do que fazer do lago tendo como finalidade a produção econômica. O cenário desenhado põe, de um lado, os moradores da região e, em especial, os pescadores; do outro, as grandes empresas e construtoras interessadas em implantar o projeto de construção do Porto Graneleiro; no outro polo, o Governo do Estado e o Federal, interessados em desenvolver a região tomando como premissa o crescimento econômico sob modelos hegemônicos de acumulação de capital transnacional. A resistência dos pescadores contra a execução desse projeto no Lago do Maicá tem como motivação principal a preservação do lago, visto que dependem desse ecossistema para garantir a sobrevivência das famílias. Conforme afirma Pimentel e Martineli (2016) “[...] o acesso aos recursos fornecidos pela natureza é imprescindível para a reprodução social das comunidades tradicionais, sejam elas quilombolas, indígenas, extrativistas, quebradores de coco, ribeirinhos ou pescadores [...]”. (PIMENTEL; MARTINELI, 2016, p.452).

Projetos de grande porte como o proposto para ser construído podem provocar transformações na paisagem do ambiente, de modo especial da paisagem da várzea, assim como, na reprodução das espécies da fauna e flora que dependem desse ecossistema para sobreviver. Para os pecadores artesanais da Região do Maicá esse é um fator preocupante uma vez que são completamente dependentes desse ambiente. Essa é uma realidade já vivenciada por pescadores artesanais do Ceará, pois, estes “[...] temem que o aumento da poluição possa causar a diminuição das capturas e redução da diversidade de espécies marinhas, o que afetaria diretamente as comunidades nativas que subsistem da exploração dessa atividade [...]". (LOPES, 2013, p. 31).

Diante dessa realidade, a Colônia de Pescadores Z-20 liderou um processo de resistência com base na lei internacional que está em vigor desde 2003, a Convenção 169 - Organização Internacional do Trabalho, que oferece um mecanismo de proteção dos direitos dos povos indígenas e tribais (MELO, 2006). Nesse caso, os pescadores enquadram-se como povos tribais ou populações tradicionais.

Para Urquidi, Teixeira e Lana, (2008) a Convenção 169:

Reconhece também o direito aos recursos naturais das terras tradicionais (utilização, administração e conservação), considerando que nos casos em que pertencer ao Estado a propriedade dos recursos existentes nas terras, seu uso deverá estar embasado em consultas aos povos interessados, reservando-se a eles a indenização por efeitos danosos que possam advir desse uso. Parte importante desse direito central é a garantia dos territórios tradicionais pelo respeito que os governos deverão ter da relação especial e dos valores espirituais que os povos dão às suas terras ou territórios, reconhecendo os direitos de propriedade e posse das terras que esses povos tradicionalmente ocupam. (URQUIDI; TEIXEIRA; LANA, 2008, p. 203-204). 
Com base nessa compreensão que os pescadores artesanais, por meio de sua entidade, uniram-se com instituições religiosas (Pastoral Social, Comissão Pastoral dos Pescadores e Comissão Pastoral da Terra), ONGs, Ministério Público Estadual e o Federal, entre outros, para ajudá-los nesse processo de luta em defesa de seu território pesqueiro. Assim, realizaram-se oficinas (Figura 1), envolvendo aproximadamente 150 pescadores, nas regiões do Ituqui, Maicá e Cidade onde tem atuação a fim de construir de forma participativa o Protocolo de Consulta dos Pescadores Artesanais.

Figura 1 - Oficina do protocolo na Comunidade de Conceição na Região do Ituqui, Várzea de Santarém (Pará)

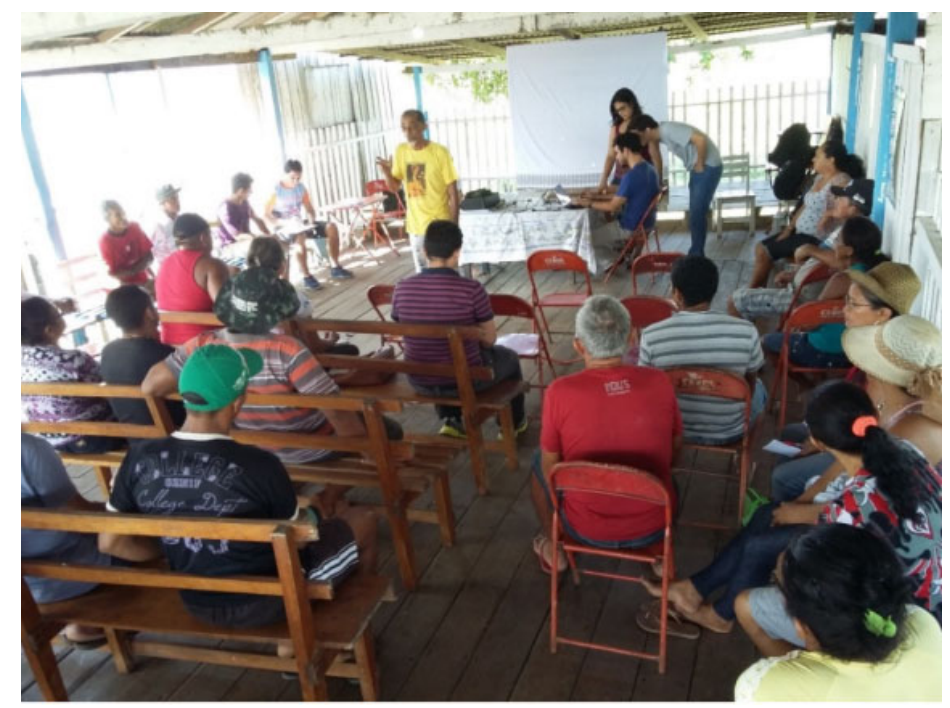

Fonte: Acervo da autora.

Após essa primeira etapa de oficinas para construção da proposta do Protocolo de Consulta Livre, Prévia e Informada, a Colônia de Pescadores Z-20 realizou uma assembleia em sua sede para apresentação e discussão do resultado colhido nas oficinas locais, nesse evento participaram aproximadamente 150 pessoas representando os núcleos de base de todo o município, bem como representantes da Comissão Pastoral dos Pescadores e ONGs que ajudaram a condução do referido evento (Figura 2).

Figura 2 - Assembleia de Aprovação do Protocolo de Consulta dos Pescadores Artesanais, na Sede da Colônia de Pescadores Z-20 (Santarém, Pará)

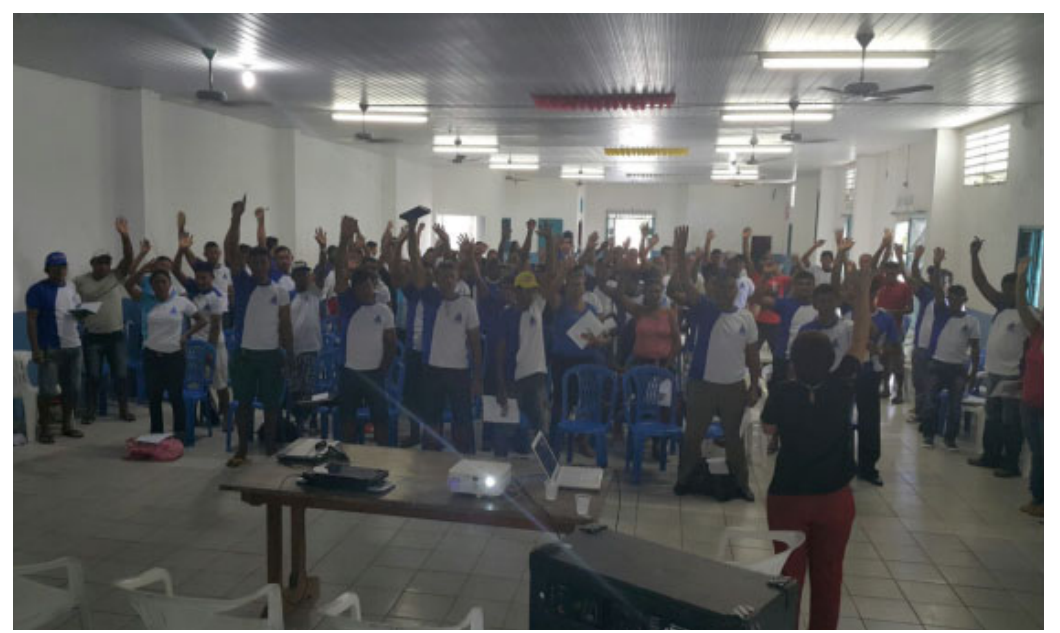

Fonte: Acervo da autora. 
O Protocolo de Consulta Livre, Prévia e Informada é um instrumento importante que nasce devido à preocupação com o projeto de instalação do Porto Graneleiro no lago. Um empreendimento desse porte e outros que fazem parte desse complexo do agronegócio instalado as margens do referido local pode afetar o recurso pesqueiro de onde os pescadores tiram seu sustento e de sua família. O Objetivo é demonstrar às instituições governamentais e privadas como esses atores sociais querem ser consultados sobre essa proposta que apresenta uma ameaça à vida, à sustentabilidade do ecossistema e a preservação dos recursos para a presente e futuras gerações.

Desde a virada do milênio, Santarém passou a compor a estratégia do agronegócio brasileiro tornando-se umas das cidades-polo de implantação de grandes empreendimentos como portos graneleiros, provocando intensos debates e conflitos, entre as organizações comunitárias de (pescadores, quilombolas, indígenas, entre outros) e as instituições privadas e públicas.

A consulta Prévia, Livre e Informada é um direito garantido na convenção 169 da Organização Internacional do Trabalho, comissão complementar da Organização das Nações Unidas, que assegura o direito dos povos tradicionais de serem consultados antes, durante e depois, de qualquer tipo de empreendimento que seja capaz de impactar o modo de vida das populações tradicionais. Esse é um avanço importante para a garantia dos direitos das comunidades tradicionais de manter sua integridade, autonomia e fortalecimento frente às consequências provocadas pelos projetos de exploração econômica em seus territórios. Além disso, serve de subsídio para o ordenamento do território onde sejam considerados os pescadores artesanais como atores sociais que habitam no ambiente e dele dependem para viver. (URQUIDI; TEIXEIRA; LANA, 2008).

\section{CONSIDERAÇÕES FINAIS}

Este artigo teve a finalidade principal de entender como ocorre o processo organizativo dos pescadores e sua metodologia de resistência em defesa de seu espaço pesqueiro é essencial para ajudar no debate de políticas públicas e no fortalecimento da categoria em Santarém.

A região de Santarém tem sido palco de intensas lutas e conflitos, onde os pescadores artesanais têm conseguido regulamentar o acesso aos recursos pesqueiros, principalmente em regiões lacustres (FERREIRA, 2018; HARTMANN, 1989). A defesa desses territórios por parte das comunidades no entorno foi propulsionada pela emergência de garantir não apenas o acesso às águas e aos recursos pesqueiros presentes no lago, mas, inclusive, na manutenção da organização social das comunidades que estão aí intergeracionalmente. E cada vez mais as comunidades varzeiras, ribeirinhas e lacustres têm se mobilizado na região santarena de modo a garantir a sustentabilidade ecológica dos ambientes aquático-terrestres (SILVA, 2018; FERREIRA, 2018; ALMEIDA, 2006; GAMA, 2016).

A atividade da pesca artesanal desenvolve função essencial na dinâmica econômica, social e ambiental local, regional e nacional, sendo responsável direta pela garantia da segurança alimentar e nutricional da população. Além disso, cumpre um papel econômico importante na vida dessas comunidades. Elas são verdadeiros territórios ambientais (ESTERCI, 2014), uma vez que elas garantem a manutenção e preservação do lago, pois o labor aí desempenhado tem pouco impacto ecológico no ecossistema lacustre. 
Ao observar a realidade socioeconômica dos pescadores artesanais do Lago do Maicá, podemos enumerar várias problemáticas socioambientais que, superpostas, esquematizam a sustentação do ecossistema lacustre como base importante para a obtenção de recursos ricos em proteínas para a dieta local. É nesse sentido que a dimensão da questão agrária na Amazônia é a luta dos ribeirinhos pelo controle do território aquático e pela manutenção e conservação dos recursos pesqueiros. (MAYBURY-LEWIS, 1997; SILVA, 2017). Segundo a conceituação anterior e atrelando-a a aspectos de mobilização política, pensamos que

Neste contexto, os Acordos de Pesca mostram-se importantes como estratégias de administração pesqueira, os quais reúnem um número significativo de comunidades de pescadores e definem normas específicas, regulando, assim, a pesca de acordo com os interesses da população local e com a preservação dos estoques pesqueiros [...] Esses Acordos limitam o acesso a certos corpos d'água, para certos apetrechos, para certas épocas do ano, para certos métodos de pesca e para certas espécies, contribuindo assim para a diminuição da pressão sobre o uso dos recursos pesqueiros em nível local. Vale-se salientar, ainda, que o processo de Acordo de Pesca tem se instituído em importante instrumento de redução de conflitos sociais no âmbito da pesca. (CARDOSO et al., 2018, p. 325).

Percebe-se que apesar de sua grande contribuição com a economia local os pescadores artesanais vivem constantemente lutando pela defesa de seu território pesqueiro. Como vimos aqui, a construção de acordos de pesca foi um crucial dispositivo legal de ordenamento intercomunitário que assegurou a sustentabilidade dos estoques pesqueiros e o disciplinamento de como entrar no lago, em quais condições e em que época.

Os projetos de desenvolvimento pensados para a região, como a construção do porto, é uma séria ameaça ao modo de vida dessas comunidades. Como frisamos ao longo do texto, o lago não é visto apenas na sua dimensão econômica: é percebido como território onde as malhas e as redes se desenvolvem, onde afetos, solidariedades, acordos e consensos são administrados e reforçados tendo como pressuposto a sobrevivência dos grupos ali investidos.

O empoderamento desses atores emerge justamente no reconhecimento das diferenças a partir dos interesses que emergem nos mais diversos atores presentes na trama do conflito: comunidades ribeirinhas-lacustres, empresas, ONGs, Estado e suas ramificações em diversos órgãos. Sem dúvida, é isso o que normalmente provoca conflitos internos e externos isso devido aos interesses serem divergentes com as instituições governamentais e privadas.

O desafio que daí desponta é como os pescadores artesanais vão redimensionar esse empoderamento, as redes de solidariedade e respeito mútuo para lidar com os desdobramentos desse processo nos possíveis futuros.

\section{REFERÊNCIAS}

AMORIM, Christina. História das Colônias de Pescadores no Brasil.Jornal

Martim-Pescador, n. 125 - Ano X, Martim-Pescador, Mai/2014. Disponível: <http:www.jornalmartimpescador.com.br>. Acesso em: 05 jan. 2017.

ALMEIDA, Bruna G. D. Os Acordos de Pesca na Amazônia: uma perspectiva diferenciada de gestão das águas. (2006). In: XV Encontro preparatório do CONPEDI/ UNICAP. Recife. Anais. Disponível em: <http://www.publicadi- 
reito.com.br/conpedi/manaus/arquivos/anais/recife/direito_ambiental_bruna almeida.pdf $>$. Acesso em: 10 out.2016.

BRASIL. Instrução Normativa IBAMA, n. 29, de 31 de dezembro de 2002. Dispõe sobre os Acordos de Pesca como um instrumento complementar de ordenamento pesqueiro e como forma de prevenir danos ambientais e sociais. Brasília 01 de janeiro de 2003.

CARDOSO, Marcélia Castro; SILVA, Rubens Elias da; SILVA, Alesandra Dyana Branches; CHIBA, Elionora da Silva Alves. Pescadores artesanais, conflito de interesses e os recursos pesqueiros vistos como capital natural crítico: o caso do Lago do Juá em Santarém, Pará.Revista O Social em Questão - v. 21, n. 40, p. 309-332, jan./abr., 2018.

CARTILHA COLÔNIA DE PESCADORES. Colônias de pescadores. Santarém Baixo Amazonas, Pará. 2004. Disponível em: <http://documentslide.com/ Documents/cartilha-colonia-de-pescadores-55a $0 \mathrm{fb} 3 \mathrm{dab} 4 \mathrm{de} . \mathrm{html}>$. Acesso em: 15 out. 2016.

CASTRO, Fábio de; MCGRATH, David. O manejo comunitário de lagos na Amazônia. Biodiversidade, pesquisa e desenvolvimento na Amazônia. Parcerias Estratégicas - n. 12, p.112-126, set., 2001.

CERDEIRA, Regina Glória Pinheiro. Projeto "Acordos de Pesca, alternativa para manejo de recursos pesqueiros". Relatório de Atividades. Conflicto y Colaboración en el Manejo de Recursos Naturales en America Latina y Caribe CyC. Instituto Amazônico de Manejo Sustentável dos Recursos Ambientais. 2002. p. 27.

CERDEIRA, Regina Glória Pinheiro; CAMARGO, Serguei Aily Franco de. Gestão participativa da pesca na região do Maicá, em Santarém, PA: reflexões jurídicas e ambientais. In: XVI CONGRESSO NACIONAL DO CONPEDI, 16, 2008. Belo Horizonte. Anais. Florianópolis: Editora Fundação Boiteux, 2008. p. 4489-4507. Disponívelem: $<$ http://www.conpedi.org.br/manaus/anais_ conpedi_bh.htm>. Acesso em: 20 mai. 2017.

CHEREM, Maria Fernanda; AZEVEDO, Natália Tavares de. Conflitos socioambientais e processos de resistência de pescadores artesanais no litoral do Paraná. $40^{\circ}$ Encontro Anual da ANPOCS. SPG 03 - As Ciências Sociais e as populações costeiras: territórios e conflitos. Anais... 2016. Disponível em: $<$ https://anpocs.com/index.php/papers-40-encontro/spg-3/spg03-3/10010-conflitos-socioambientais-e-processos-de-resistencia-de-pescadores-artesanais-no-litoral-do-parana/file>. Acesso em: 20 mai.2017.

COLÔNIA DE PESCADORES Z-20. ESTATUTO SOCIAL DA COLÔNIA DE PESCADORES Z-20 - SANTARÉM. Alterado por meio da Assembleia Geral Extraordinária, exclusivamente para este fim, na data de 29/06/2012, p. 11.

DIEGUES, Antônio Carlos. O mito moderno da natureza intocada. 3 Ed. Editora Hucitec. Núcleo de Apoio à Pesquisa sobre Populações Humanas e Áreas Úmidas Brasileiras/USP. São Paulo, 2001. p. 102.

ESTERCI, Neide. Cientistas e povos da floresta: a invenção de novos territórios de proteção ambiental na Amazônia. In: ESTERCI, Neide; SANTANNA JUNIOR., Horácio Antunes de; TEISSERENC, Maria José Aquino (org.). Territórios socioambientais em construção na Amazônia brasileira. Rio de Janeiro: 7 Letras, 2014, p. 21-38.

FERREIRA, Roberth Rodrigues. Gestão da pesca na Ilha de São Miguel, Santarém, Pará: mobilização política para acesso, uso e controle dos recursos pesqueiros locais. Dissertação. (Mestrado em Sociedade, Ambiente e Qualidade de Vida) Centro de Formação Interdisciplinar, Universidade Federal do Oeste do Pará, Santarém, 2018.

GAMA, Antonia do Socorro Pena da. Educação Ambiental e a Construção da Sustentabilidade na Região de Várzea de Santarém (Pa)-Brasil. Tese. (Dou- 
torado em Educação) Faculdade de Educação, Universidade de Campinas, Campinas, 2016.

GOHN, Maria da Glória. Empoderamento e participação da comunidade em políticas sociais. Saúde e Sociedade, São Paulo, v. 6, n.1, p. 20-31, 2005.

. Movimentos sociais: espaço de aprendizagem coletiva. Revista de Educação CEAP, Salvador, Ano 12, n. 46, p. 5-17, 2004.

HARTMANN, Wolf D. Conflitos de pesca em águas interiores da Amazônia e tentativas para sua solução. In: DIEGUES, A. C. (Ed.). Pesca Artesanal: Tradição e Modernidade. São Paulo: Encontro de Ciências Sociais e o Mar no Brasil, 3. Anais... 1989. p. 103-118.

KALIKOSKI, Daniela; DIAS NETO, J.; THÉ, A. P. G.; RUFFINO, M. L.; MARRUL FILHO, S. Gestão compartilhada do uso sustentável de recursos pesqueiros: refletir para agir. Brasília: Ibama, 2009.184p.

LEROY, Jean-Pierre. O bote contra a geleira. Os pescadores de Santarém em busca da sua afirmação. In: Pescadores artesanais - Entre o passado e o futuro. Revista Proposta.. Rio de Janeiro, v. 38, p. 37-50, set., 1988.

LITTLE, Paul E. Os conflitos socioambientais: um campo de estudo e de ação política. In: BURSZTYN, M. (Org.). A dificil sustentabilidade: política energética e conflitos ambientais. Rio de Janeiro: Garamond, 2001. p. 107-122.

LOPES, Alissandra Pinheiro. Territorialidades em conflito na Baía de Sepetiba, Rio de Janeiro, Brasil. Estudo de caso dos conflitos entre os pescadores artesanais e o porto da Companhia Siderúrgica do Atlântico (ThyssenKrupp CSA).2013. Dissertação (Mestrado em Ciência Ambiental) Universidade de São Paulo, São Paulo, 2013.

MAYBURY-LEWIS, Bjorn. Terra e água: identidade camponesa como referência de organização política entre os ribeirinhos do Rio Solimões. In: FURTADO, Lourdes G. (Org.). Amazônia, desenvolvimento e qualidade de vida. Belém: UFPA/NUMA, 1997. p. 31-69.

MELO, Mario. Últimos avances em la justiciabilidad de los derechos indígenas en el sistema interamericano de derechos humanos.SUR - Revista Internacional de Direitos Humanos, n. 4, v. 3, p. 31-49, 2006. PESSANHA, Elina Gonçalves da Fonte. Os companheiros: Trabalho e sociabilidade na pesca de Itaipu. Niterói: Eduff, 2003. (Série Antropologia e Ciência Política).

PIMENTEL, Karen Daniele de Araújo; MARTINELI, Letícia Veloso.Luta e resistência da tradição no espaço urbano: o caso da vila dos pescadores do Jaraguá. Revista InSURgência. Brasília, v. 2, n. 1, p. 443-477, 2016.

PINTO, Márcia Freire; NASCIMENTO, João Luís Joventino; BRINGEL, Paula Cunha Ferreira; MEIRELES, Antônio Jeovah de Andrade. Quando os conflitos socioambientais caracterizam um território? Revista Gaia Scientia. Volume Especial Populações Tradicionais, p. 271-288, 2014.

RAFFESTIN, Claude. Por uma geografia do poder. São Paulo: Ática, 1993.

ROOSEVELT, A. C.; HOUSLEY, R.A.; SILVEIRA, M.I.; MARANCA, S. \& JOHNSON, R. Eighth millenium pottery from a prehistoric shell midden in the Brazilian Amazon. Science, v. 254, p. 1557-1696, 1991.

SANTOS, Marcos Antônio Souza dos. A Cadeia Produtiva da Pesca Artesanal no Estado do Pará: estudo de caso no nordeste paraense. Amazônia: Cia. \& Desenvolvimento. Belém, v. 1, n. 1, jul./dez., 2005.

SAQUET, Marcos Aurélio. Campo-Território: considerações teórico-metodológicas. Campo-Território. Uberlândia, v. 1, n. 1, p. 60-81, fev., 2006.

SILVA, Luiz Geraldo Santos da. Pescadores, Militares e Burgueses: Legislação Pesqueira e Cultura Marítima no Brasil (1840 - 1930). Dissertação. (Mestrado em História) Centro de Filosofia e Ciências Humanas, Universidade Federal de Pernambuco, Recife, 1991. 
SILVA, Yure Adriano Rocha da. Agricultura Mecanizada e Expansão Urbana em Santarém-PA: Padrões e Processos Espaciais. Trabalho de Conclusão de Curso. (Graduação em Licenciatura Plena em Geografia) Universidade Federal do Oeste do Pará, Santarém, 2014.

SILVA, Rubens Elias da. Guiados por Mares e Peixes: memória social, inovação tecnológica e o processo de fragmentação na pequena pesca comercial simples em duas comunidades costeiras no Rio Grande do Norte. Tese (Doutorado em Sociologia) Universidade Federal da Paraíba. João Pessoa, 2012.

. Por uma reforma agrária aquática? Luta por reconhecimento social dos ribeirinhos do rio tapajós para a construção de Acordos de Pesca.Revista Ciências da Sociedade.Santarém, v. 1, n. 2, p. 81-102, 2017.DOI: 10.30810/ res.v1i2.477.

SILVA NETO, Nirson Medeiros; SANTOS, Alessandro de Oliveira. Justiça restaurativa e conflitos sociais envolvendo comunidades tradicionais na Amazônia brasileira: um estudo de caso no município de Santarém, Pará. Revista Ciências da Sociedade. Santarém, v. 2, n. 3, p. 238-259,2018. DOI: 10.30810/ res.v2i3.629 .

SILVEIRA, Maura Imazio; SCHAAN, Denise Pahl. Onde a Amazônia encontra o mar: estudando os sambaquis do Pará. Revista de Arqueologia, v. 18, p. 67-79, 2005.

SOUSA, Wandicleia Lopes. Caracterização Econômica e Social dos Pescadores Artesanais no Bairro Pérola Maicá, no Município e Santarém-Pará. Trabalho de Conclusão de Curso. (Graduação em Ciências Econômicas) Instituto de Ciências da Sociedade, Universidade Federal do Oeste do Pará, Santarém, 2017.

URQUIDI, Vivian; TEIXEIRA, Vanessa; LANA, Eliana. Questão Indígena na América Latina: Direito Internacional, Novo Constitucionalismo e Organização dos Movimentos Indígenas. Cadernos PROLAM/USP, v. 8, n. 1, p. 199-222, 2008.

VAZ, Elizabete de Matos. Caracterização da atividade pesqueira praticada no Lago Maicá, Município de Santarém, Pará.Trabalho de Conclusão de Curso. (Graduação em Engenharia de Pesca) Instituto de Ciências e Tecnologia das Águas, Universidade Federal do Oeste do Pará, Santarém, 2016. 